\title{
Publisher's Note: Optomechanical systems close to the conservative limit [Phys. Rev. A 95, 013831 (2017)]
}

D. Platou Foulla, P. Djorwé, S. Takougang Kingni, and S. G. Nana Engo

(Received 3 May 2017; published 10 May 2017)

DOI: 10.1103/PhysRevA.95.059906

This paper was published online on 23 January 2017 with an incorrect author affiliation and footnote, as well as an omission in the Acknowledgments. The affiliation of the second author, P. Djorwe, should read as "Department of Physics, University of Jyväskylä, Finland”; the footnote should read as "philippe.p.djorwe@jyu.fi." On page 4, the last sentence of the Acknowledgments should read as "P.D. is grateful to the Academy of Finland for the financial support." The paper has been corrected as of 1 May 2017. The affiliation, footnote and Acknowledgments are incorrect in the printed version of the journal. 